\title{
PROCESSOS PEDOGENÉTICOS E SUSCEPTIBILIDADE DOS SOLOS À DEGRADAÇÃO NO SEMIÁRIDO BRASILEIRO
}

\author{
Rodrigo Santana Macedo \\ Instituto Nacional do Semiárido, Campina Grande, PB, Brasil \\ macedo-rs@hotmail.com \\ Raphael Moreira Beirigo \\ Universidade Federal da Paraíba (UFPB) \\ Departamento de Solos e Engenharia Rural, Areia, PB, Brasil \\ rmbeirigo@yahoo.com.br \\ Beatriz Macêdo Medeiros \\ Universidade do Estado de Santa Catarina (UDESC), Lages, SC, Brasil \\ bemacedom@gmail.com \\ Victor Junior Lima Felix \\ Universidade Federal da Paraíba (UFPB) \\ Departamento de Solos e Engenharia Rural, Areia, PB, Brasil \\ victorfelixif@gmail.com \\ Renato Francisco da Silva Souza \\ Universidade Federal da Paraíba (UFPB) \\ Departamento de Solos e Engenharia Rural, Areia, PB, Brasil \\ renatofssouza@live.com \\ Alexandre Pereira de Bakker \\ Instituto Nacional do Semiárido, Campina Grande, PB, Brasil \\ bakker1000@yahoo.com
}

\begin{abstract}
RESUMO
As relações dos processos pedogenéticos específicos e a susceptibilidade dos solos à degradação no semiárido nordestino ainda não foram satisfatoriamente esclarecidas. Esse entendimento pode subsidiar intervenções e políticas públicas que atenuem e/ou revertam à degradação dos solos. O objetivo dessa pesquisa foi avaliar a relação entre processos pedogenéticos específicos e a susceptibilidade dos solos a degradação/desertificação nas microrregiões do Seridó e Cariri. Foram atualizadas as classes de solos das unidades de mapeamento (UM) dos estados da Paraíba e Rio Grande do Norte. Essas novas UM foram sobrepostas com áreas fortemente degradadas (AFD). Áreas degradadas estão predominantemente associadas com Luvissolos Háplicos Pálicos abrúpticos e Neossolos Litólicos Eutróficos típicos e fragmentários no Seridó e com Luvissolos Crômicos Órticos típicos e vertissólicos no Cariri. O predomínio da agropecuária na maioria das AFD confirma a forte pressão antrópica sobre o meio ambiente. A mudança textural abrupta aumenta a susceptibilidade dos Luvissolos e Planossolos à degradação. Antrossolização pode acelerar a erosão, salinização, sodificação e solodização. Como consequência tem-se perdas de solos, de sua qualidade física e assoreamento de corpos hídricos. As relações entre processos pedogenéticos e degradação das terras são compreendidas com a avaliação dos solos em níveis categóricos mais elevados (subgrupo).
\end{abstract}

Palavras-chave: Caatinga. Propriedades dos solos. Antrossolização. Desertificação.

\section{PEDOGENETIC PROCESSES AND SUSCEPTIBILITY OF SOILS TO DEGRADATION IN THE BRAZILIAN SEMIARID REGION}

\section{ABSTRACT}

The relationship between specific pedogenic processes with soil susceptibility to degradation in the Northeastern semiarid region of Brazil is not yet well understood. This knowledge is important duo to the possibility of subsidizing interventions and public policies, 
which may contribute to mitigate and/or reverse soil degradation. The aim of this study was to evaluate the relationship between specific pedogenic processes and soil susceptibility to land degradation and/or desertification in the microregions of Seridó and Cariri, located in Rio Grande do Norte and Paraíba states, respectively. Soil classes of the mapping units (MU) of these areas were updated and overlayed with heavily degraded areas (HAD). Degraded are mainly associated with Abruptic Luvisol (Clayic) and Eutric Leptosol (Arenic) in the Seridó and Haplic Luvisol (Clayic) in the Cariri. The predominance of agriculture in most HAD confirms the strong anthropic pressure on the environment. Abrupt textural difference increases the susceptibility of Luvisols and Planosols to degradation. The anthrossolization can accelerate erosion, salinization, sodification, and solodization, causing soil loss, reducing soil physical quality, and siltation of water bodies. The relationship between specifics pedogenetic processes and land degradation can be better understood by assessing soils at higher categorical levels (subgroup).

Keywords: Caatinga. Soil properties. Anthrossolization. Desertification.

\section{INTRODUÇÃO}

A degradação das terras em áreas de climas áridos, semiáridos e subúmidos secos implica na redução ou perdas da produtividade biológica ou econômica, das áreas de cultivo de sequeiro e irrigadas, pastagens, florestas e bosques resultantes do uso da terra ou da combinação de processos decorrentes de atividades humanas e padrões de habitação (UNCCD, 2017). Nessas terras secas ocorre a desertificação, entendida como um conjunto de processos que causam gradualmente à perda dos solos ou à perda da sua capacidade produtiva, a supressão da vegetação e a deterioração da qualidade dos corpos hídricos (CGEE, 2016; UNCCD, 2017).

Assim como muitos outros processos que acarretam a degradação dos ecossistemas, a desertificação tem origem em fatores naturais que podem ser acelerados por atividades antrópicas, ações essas que podem ocorrer concomitantemente ou de forma isolada. A observação de que esse processo pode transformar alguns locais em verdadeiros desertos, onde a vegetação e os solos encontram-se em condições irrecuperáveis, levou a identificação de alguns locais como "núcleos de desertificação", compreendidos como verdadeiros desertos dentro de ecossistemas primitivos (VASCONCELOS SOBRINHO, 1978).

Ao longo das últimas décadas inúmeros esforços foram realizados para mapear e criar metodologias para entender e frear o avanço do fenômeno da desertificação, bem como formular indicadores para dimensionar o problema e que permitissem comparações de situações (MATALLO JUNIOR, 2001; MMA, 2005; SOUZA e OYAMA, , 2011; SOUSA et al., 2012; VIEIRA et al., 2015; CGEE, 2016; TOMASELLA et al., 2018; VENDRUSCOLO et al., 2020; entre outros). Como resultado desse empenho foram identificados locais mais críticos do ponto de vista físico que requerem esforços da comunidade científica e dos poderes públicos para o desenvolvimento de ações que possam atenuar, remediar ou impedir o avanço da desertificação. Essas áreas estão fortemente degradadas e em processo de desertificação e informações sobre os solos são fundamentais para o desenvolvimento de tecnologias para o monitoramento e recuperação destas áreas.

As características ambientais que qualificam o ambiente físico do semiárido em graus de susceptibilidade à degradação são solos rasos a pouco profundos, afloramentos rochosos, pedregosidade, escoamento superficial intenso com erosão e ravinamentos e impermeabilidade do substrato rochoso (BRASIL, 1971; 1972; CGEE, 2016). Tal susceptibilidade é intensificada quando há degradação da cobertura vegetal, notadamente para produção de lenha e carvão para fins energéticos, causando mudanças nas propriedades físicas dos solos, intensificando o escoamento superficial e os processos morfodinâmicos (erosão), promovendo modificações da drenagem interna, alterando processos pedogenéticos e comprometendo a recarga dos aquíferos (CGEE, 2016).

As intervenções antrópicas, fatores climáticos e os atributos dos solos têm sido apontados como causadores da desertificação (PEREZ-MARIN et al., 2012; VENDRUSCOLO et al., 2020). Os atributos dos solos formados a partir de processos pedogenéticos podem determinar a capacidade de resistência e resiliência dos ecossistemas. Esses processos são desencadeados inicialmente a partir do intemperismo do material de origem, influenciado diretamente pela atuação do clima, notadamente temperatura e precipitação, sob ação dos organismos e controle do relevo local (YOUNG, 1976).

Os processos pedogenéticos podem ser acessados a partir dos atributos morfológicos, os quais influenciam as propriedades físicas e químicas dos solos (WILDING; SMECK; HALL, 1983a, 1983b). Logo, admite-se que as relações entre os fatores de formação e os solos são reais somente quando consideradas em conjunto com processos pedogenéticos, o que habilita o emprego dessa abordagem 
no âmbito da problemática da desertificação a fim de acessarmos as relações existentes entre o ambiente, o funcionamento dos solos e suas funções externas.

É necessário identificar e quantificar a ação dos fatores e processos pedogenéticos para compreendermos os mecanismos envolvidos no processo de desertificação, buscando estabelecer condições de predisposição dos solos com o estabelecimento e expansão da desertificação. Nesse contexto, o panorama da desertificação no Nordeste brasileiro recomenda primariamente a atualização da classificação dos solos e das unidades de mapeamento (UM) dos mapas pedológicos como ferramenta prioritária para gestão dos recursos naturais, combate à desertificação e mitigação dos efeitos das secas, pois as informações pedológicas atualmente disponíveis para muitos estados do Nordeste, como é o caso do Rio Grande do Norte (RN) e da Paraíba (PB) encontram-se em levantamentos em nível exploratório ou de reconhecimento (BRASIL 1971;1972) e em área-piloto no limite entre esses estados (SILVA et al., 2002). Atualizou-se as informações pedológicas das microrregiões do Seridó (RN e PB) e do Cariri (PB) relacionando-as com áreas fortemente degradadas (AFD) em processo de desertificacãa identificadas pelo Centro de Gestão e Estudos Estratégicos (CGEE, 2016). Dado o avançado estágio de degradação e a representatividade geográfica na região semiárida, estudos nessas áreas certamente permitirão extrapolações seguras sobre as propriedades e dinâmica dos solos no âmbito da problemática da desertificação.

Portanto, essa pesquisa pretendeu responder alguns questionamentos ainda em aberto, notadamente em áreas em processo de desertificação do Seridó nos estados do Rio Grande do Norte e Paraíba e do Cariri na Paraíba, a saber: a) Que processos podem ser acelerados pelo homem e quais são de ocorrência natural? b) Como esses processos influenciam a susceptibilidade dos solos a degradação? O objetivo dessa pesquisa foi avaliar às relações existentes entre processos pedogenéticos e a susceptibilidade dos solos da microrregião do Seridó (RN e PB) e Cariri (PB) ao processo de degradação/desertificação.

\section{MATERIAL E MÉTODOS}

\section{Localização da área de estudo}

A área de estudo está localizada na microrregião do Seridó dos estados do Rio Grande do Norte e Paraíba (Figura 1). Essa microrregião abrange 54 municípios, sendo 28 no estado do Rio Grande do Norte e 26 no estado da Paraíba, totalizando uma área de $20.180 \mathrm{~km}^{2}$ (IBGE, 2015; SUDENE, 2017). Ambas as áreas pertencem ao clima semiárido quente (BSh) pela classificação de Köppen (ALVARES et al., 2013), caracterizado pela ocorrência de precipitações pluviométricas médias anuais muito baixas e irregulares. A vegetação primária é Savana-Estépica Florestada (caatinga hipoxerófila), Savana-Estépica Arborizada e Savana-Estépica Gramíneo-Lenhosa (caatinga hiperxerófila) (BRASIL, 1971; 1972; IBGE, 2012).

Figura 1 - Localização da área de estudo. Mapa do Brasil, região Nordeste, semiárido brasileiro, estado do Rio Grande do Norte (RN) e Paraíba (PB) e microrregiões do Seridó e Cariri.

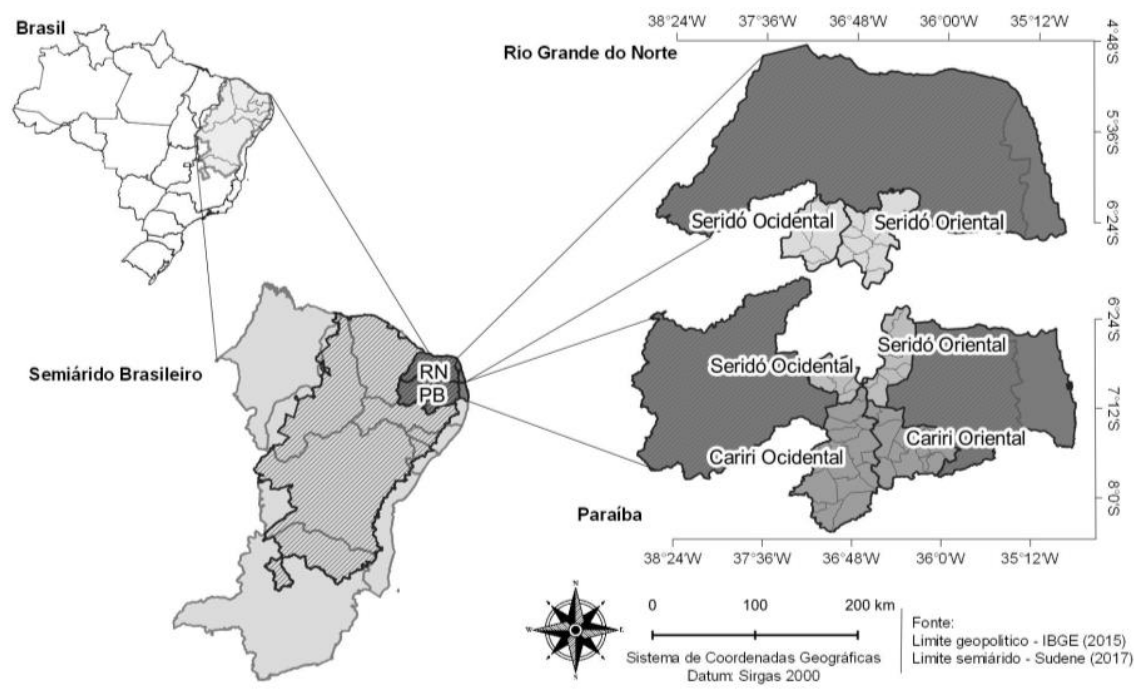

Org. - Autores, 2020. 
No Seridó as rochas são granitóides Brasilianos e do Domínio Rio Piranhas-Seridó. Os granitoides Brasilianos são diques de rochas graníticas leucocráticas e as do Domínio Rio Piranhas-Seridó são micaxistos, anfibolitos e biotita-xistos da Formação Seridó e quartzitos, rochas calcissilicáticas e micaxistos da Formação Equador (MEDEIROS; NESI; NASCIMENTO, 2010). Essa microrregião está inserida nos domínios geomorfológicos da Depressão Sertaneja e do Planalto da Borborema, com pequenas cristas e esparsas superfícies planálticas e alguns segmentos destacados com relevo montanhoso e os Planaltos Residuais Sertanejos onde predominam relevos elevados em formas de platôs ou maciços montanhosos (MEDEIROS; NESI; NASCIMENTO, 2010).

As rochas que ocorrem no Cariri da Paraíba são gnaisses, quartzitos, anfibolitos e migmatitos da litoestratigrafia Terreno Alto Moxotó e partes do Terreno Rio Capiparibe (SANTOS; FERREIRA; SILVA JUNIOR, 2002). No Planalto da Borborema, ocorrem restos de capeamento sedimentares elevados e as áreas cristalinas elevadas, incluindo maciços residuais e inselbergs, como unidades geomorfológicas locais (BRASIL, 1972).

\section{Levantamento de dados e classificação dos solos}

Foram selecionadas todas as unidades de mapeamento (UM) dos levantamentos de solos de ocorrência nas microrregiões do Seridó e Cariri, dos Levantamentos Exploratórios-Reconhecimento de Solos dos Estados da Paraíba e do Rio Grande do Norte (BRASIL, 1971; 1972). Para facilitar a identificação das UM também foram utilizados os mapas disponibilizados no portal Solos do Nordeste da Embrapa Solos (EMBRAPA, 2006). Após a identificação das UM, os dados morfológicos, físicos e químicos dos solos representativos de cada componente das associações foram digitalizados. Nesse processo a nomenclatura de horizontes e algumas propriedades morfológicas foram atualizadas, bem como, calculados alguns critérios diagnósticos (p. ex., atividade da fração argila, mudança textual abrupta). A partir dessas informações foram identificados os atributos diagnósticos, caracterizados os horizontes diagnósticos e classificados os solos conforme o Sistema Brasileiro de Classificação de Solos 5aㅡ edição - SiBCS (EMBRAPA, 2018). As UM com a classificação dos solos atualizada foram sobrepostas com AFD no Seridó e Cariri (CGEE, 2016).

A partir destas informações foram criados os mapas no aplicativo livre e de código aberto QGIS versão 3.0.3 (QGIS DEVELOPMENT TEAM, 2020). Foram utilizados arquivos vetoriais no formato shapefile dos polígonos das unidades de mapeamento e limites geopolíticos disponibilizados gratuitamente. Após a delimitação das AFD em processo de desertificação (CGEE, 2016), os mapas do Rio Grande do Norte e Paraíba foram georreferenciados e os respectivos polígonos foram digitalizados e sobrepostos nas UM. O mapa de solos foi elaborado a partir das UM disponibilizadas pela Embrapa (2006). A padronização das cores foi realizada conforme o SiBCS (EMBRAPA, 2018). O mapa de uso e cobertura do solo foi gerado a partir de arquivos raster disponibilizado pela plataforma MapBiomas Brasil (2019). A padronização de cores dos polígonos também seguiu recomendações do MapBiomas. A classificação de uso e cobertura da terra foi realizada conforme especificações constantes em Souza Junior et al. (2020).

\section{RESULTADOS E DISCUSSÃO}

\section{Unidades de levantamento de solos do Seridó e Cariri}

No Seridó Oriental do Rio Grande do Norte (RN) predominam Neossolos Litólicos Eutróficos (RLe). São os primeiros componentes das UM em Acari, Currais Novos, Equador, Jardim do Seridó, Parelhas e Santana do Seridó, ocupando área de 79.612,01 ha (Figura 2). Constituem ainda o segundo componente de associações com Luvissolos Crômicos Órticos - TCo (55.834,47 ha) e Luvissolos Háplicos Pálicos TXp (147.228,57 ha). Em Acari, Carnaúba dos Dantas, Parelhas, Santana do Seridó e São José do Seridó encontram-se associados com Neossolos Regolíticos Psamíticos - RRq (21.110,11 ha). Esses RLe, que são solos rasos $(20-30 \mathrm{~cm})$ e com elevados teores de nutrientes, ocorrem em relevo suave ondulado a montanhoso e apresentam horizonte $\mathrm{A}$ assente diretamente sobre a rocha gnáissica ou granítica (Brasil, 1971).

No Seridó Ocidental do RN os TXp ocupam 158.574,89 ha (Figura 2). Em Caicó, Cruzeta e Ouro Branco predominam TCo, ocupando uma área de 55.834,47 ha (Figura 2). Esses Luvissolos são 
Processos pedogenéticos e susceptibilidade dos solos à degradação no semiárido brasileiro
Rodrigo Santana Macedo

Raphael Moreira Beirigo

Beatriz Macêdo Medeiros

Victor Junior Lima Felix

Renato Francisco da Silva Souza Alexandre Pereira de Bakker

caracterizados pelo incremento de argila em profundidade $(\mathrm{Bt})$ e elevada capacidade de troca de cátions (CTC) e saturação por bases (V\%), sendo mais utilizados com agricultura e pastagem (Brasil, 1971).

Os Planossolos Háplicos (SXe) são o segundo ou terceiro componente das associações com Luvissolos e Neossolos (Figura 2). Variam de rasos a profundos e imperfeitamente drenados, onde o horizonte superficial contrasta abruptamente com o horizonte Bt argiloso (B plânico) de menor permeabilidade (Brasil, 1971). Nesses solos os teores de $\mathrm{Ca}^{2+}, \mathrm{Mg}^{2+} \mathrm{e} \mathrm{Na}^{+}$são elevados e aumentam em profundidade (eutróficos), contrastando com os teores quase nulos de $\mathrm{Al}^{3+}$. Cambissolos Háplicos Tb Distróficos (CXbd) representam o segundo componente de associações com Neossolos Litólicos (11.352,72 ha). Esses solos ocorrem em relevo ondulado e apresentam horizonte B incipiente cascalhento e contato lítico fragmentário entre $60-80 \mathrm{~cm}$.

No Seridó paraibano os RLe ocorrem em associação com afloramentos rochosos e em menor expressão com Luvissolos (73.392,71 ha). Tais associações são expressivas em Frei Martinho, Pedra Lavrada, Picuí, Seridó e Tenório. TCo associados com RLe, RRe e Planossolos Nátricos Órticos (SNo) ocupam 44.408,15 ha, distribuídos principalmente nos municípios de São José do Sabugi, Santa Luzia, Várzea, São Mamede e Salgadinho.

Latossolos Amarelos Distróficos (LAd) juntamente com Plintossolos Pétricos Concrecionários (FFc) ocorrem em Cubati (57,56 ha). Os LAd são profundos, bem drenados, homogêneos em profundidade e distróficos, enquanto os FFc são identificados pela ocorrência de camadas de concreções ferruginosas (pertroplintitas) sobrepostas por capeamento sedimentar argiloarenoso (BRASIL, 1971). Cambissolos Háplicos Tb Eutróficos (CXbe) estão associados com RRe (457,22 ha) em relevo ondulado e montanhoso, enquanto Cambissolos Háplicos Ta Eutróficos (CXve) ocorrem com SNo (11.209,04 ha) em relevo plano a suave ondulado (Figura 2).

Figura 2 - Unidades de levantamento dos solos da microrregião do Seridó (Rio Grande do Norte e Paraíba) e Cariri (Paraíba), região semiárida do Nordeste brasileiro.
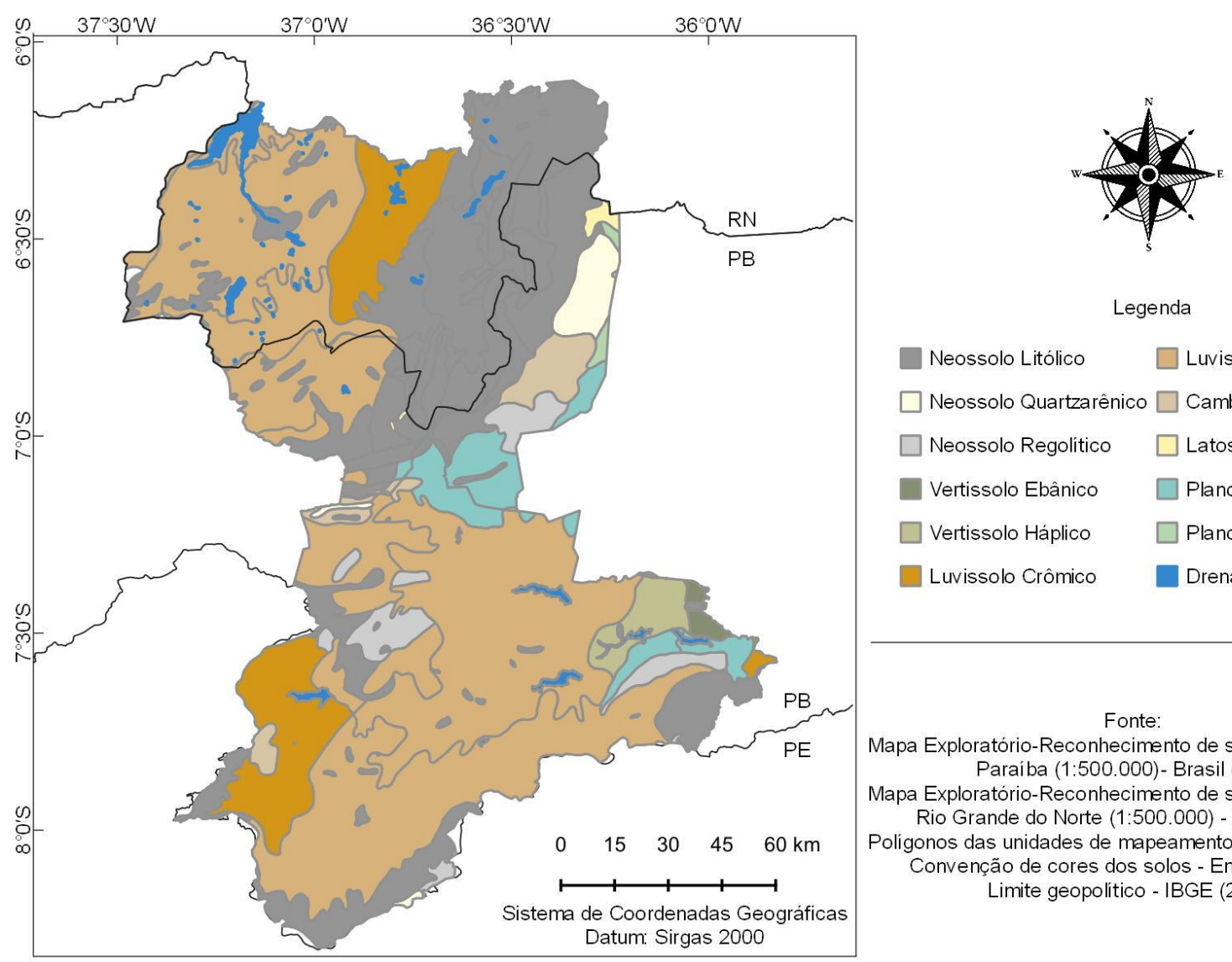

Legenda

Neossolo Litólico $\quad \square$ Luvissolo Háplico

Neossolo Quartzarênico $\square$ Cambissolo Háplico

Neossolo Regolítico

Latossolo Amarelo

Vertissolo Ebânico

Planossolo Nátrico

Vertissolo Háplico

Planossolo Háplico

Luvissolo Crômico

Drenagem

Org. - Autores, 2020. 
Em toda a extensão do Cariri predominam TCo em associação com RLe (1.793,85 ha), RRe (225.822,03 ha) e Vertissolos Háplicos Órticos - VXo (143.250,39 ha) (Figura 2). CXbe ocorrem com afloramentos de rocha $(1.083,20$ ha) e RRe $(868,28$ ha). SXe e SNe estão associados com RLe (2.476,59 ha), enquanto somente SNe ocorrem com RRe (3.230,16 ha). Os SNe apresentam horizonte B plânico com estrutura colunar e elevados teores de $\mathrm{Na}^{+}$(BRASIL, 1972). Vertissolos Ebânicos Órticos (VEo) ocupam 1.772,67 ha no Cariri paraibano, notadamente em Barra de Santana. São solos imperfeitamente drenados que apresentam horizonte $\mathrm{C}$ com evidente fendilhamento, dada a ocorrência de argilas expansivas de atividade alta (Figura 2).

\section{Solos e cobertura vegetal no Seridó e Cariri}

O mapa de uso e cobertura vegetal mostra de acordo com a classificação do MAPBIOMAS a Formação Savânica formada pelas fitofisionomias Savana-Estépica Florestada (caatinga hipoxerófila), Savana-Estépica Arborizada e Savana-Estépica Gramíneo-Lenhosa (caatinga hiperxerófila) ocupando 294.492,15 ha do Seridó no RN, sendo 97.626,53 ha de ocorrência em AFD (Figura 3).

Na porção Ocidental a Formação Savânica é expressiva em Caicó, Ipueira, Jardim de Piranhas, São Fernando e Serra Negra do Norte, enquanto que Acari e Cruzeta destacam-se no setor Oriental (Figura 3). Nessas áreas predominam TCo típicos e fragmentários e TXp abrúpticos, que ocorrem predominantemente em relevo suave ondulado a ondulado em vertentes com declividade entre $10 \mathrm{a}$ 20\% (BRASIL, 1971). Esses solos apresentam considerável reserva de minerais primários facilmente intemperizáveis, que atuam como fonte de nutrientes para o crescimento da maioria das plantas, inclusa a capacidade de suportar vegetação de caatinga hipoxerófila ou hiperxerófila (BRASIL, 1971). Áreas com vegetação de caatinga também são expressivas em Carnaúba dos Dantas, Equador, Parelhas e Santana do Seridó. Nesses locais predominam RLe e RRe.

Figura 3 - Cobertura do solo na microrregião do Seridó (Rio Grande do Norte e Paraíba) e Cariri (Paraíba), região semiárida do Nordeste brasileiro.

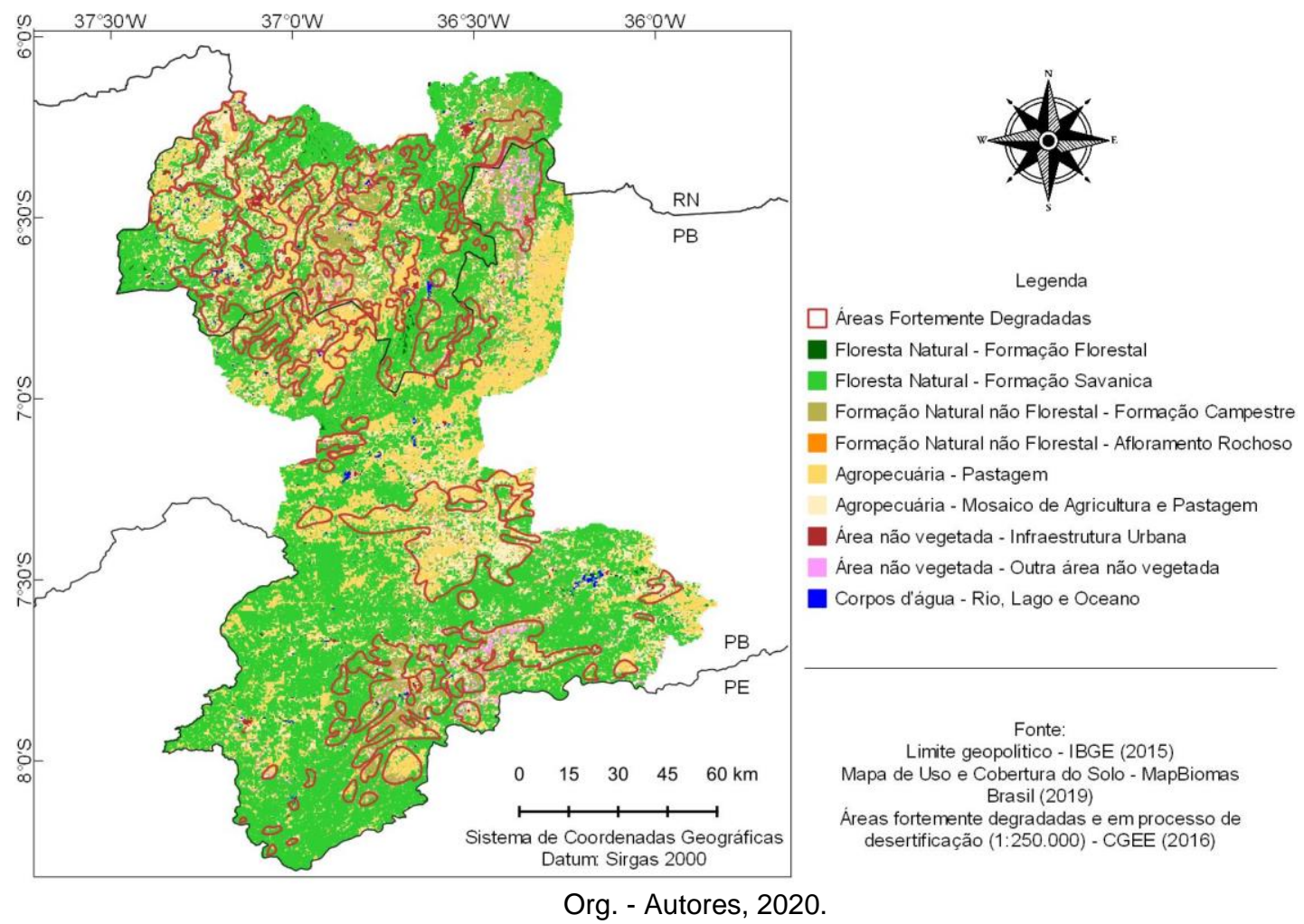

A principal utilização dos solos no Seridó do RN é para fins agropecuários (255.044,62 ha). Destes, as pastagens ocupam uma área total de 119.946,61 ha, sendo 62.847,05 ha em AFD (Figura 3). Expressivas áreas de pastagem ocorrem em Caicó, Jardim de Piranhas, São Fernando, Serra Negra 
do Norte e Timbaúba dos Batistas. Em menor proporção são encontradas em Cruzeta, Jardim do Seridó, Ouro Branco e São José do Seridó (Figura 3). Nesses municípios predominam TCo e TXp em suas diferentes tipificações. Áreas onde não é possível distinguir entre pastagem e agricultura ocupam 76.209,76 ha, sendo 135.098,01 ha em AFD.

As AFD sem vegetação (5.768,04 ha) ocorrem principalmente em Ouro Branco, Jardim do Seridó e São José do Seridó (Figura 3). Áreas moderadamente a fortemente degradadas nesses municípios (TOMASELLA et al., 2018) estão precisamente relacionadas com TCo típicos ou fragmentários. A ocorrência em relevo suave ondulado a ondulado, baixos teores de matéria orgânica, pouca profundidade e a ocorrência de mudança textural abrupta nesses solos reforçam a necessidade de manutenção da cobertura vegetal nesses locais.

Formações Campestre (Savana-Estépica Parque, Savana-Estépica Gramíneo-Lenhosa e Savana Gramíneo-Lenhosa) ocupam 104.064,84 ha do Seridó do RN, sendo 61.681,20 ha encontrados em AFD (Figura 3). Ocorrem predominantemente nos municípios de Cruzeta, Jardim do Seridó, Ouro Branco e São José do Seridó sobre TCo típicos e fragmentários. Outros 9.865,25 ha são cobertos por Formação Florestal (Savana-Estépica Florestada e Floresta Estacional Semi-Decidual e Decidual), onde apenas 1.953,25 ha são encontradas em AFD.

No Seridó paraibano a vegetação de Caatinga ocupa 168.133,15 ha, sendo encontrados $36.050,40$ ha em AFD (Figura 3). Ocorre predominantemente sobre RLe pedregosos em associação com afloramentos de rocha (Figura 3 ) que estão relacionados com maciços e cadeias de elevações residuais do Planalto da Borborema, com predomínio de rochas metamórficas e relevo ondulado a montanhoso (BRASIL, 1972). Formação Campestre ocupa uma área de 56.815,14 ha, com 25.604,31 ha ocorrendo em AFD. É expressiva em Frei Martinho, Nova Palmeira, Pedra Lavrada e Picuí, onde ocorre sobre RLe , enquanto nos municípios de São Mamede e Várzea está associada com TCo. Formação Florestal (Savana-Estépica Florestada) ocorre em apenas 2.042,34 ha, sendo 289,13 ha em AFD.

A agropecuária também é a principal utilização das áreas no Seridó paraibano (41.825,54 ha). Pastagens ocupam 133.838,90 ha, sendo 24.206,74 ha em AFD. Essas áreas são expressivas em Baraúna, Cubati, Junco do Seridó, Pedra Lavrada, Santa Luzia, São José dos Batistas e Tenório. Predominam nessas áreas RLe rasos e pedregosos (BRASIL, 1972). Áreas não vegetadas ocupam $14.462,70$ ha do Seridó paraibano, sendo 8.722,17 ha em AFD, notadamente em Frei Martinho e Picuí. Nesses municípios ocorrem sobre RLe altamente susceptíveis à degradação, devido o relevo forte ondulado a montanhoso e pela presença de horizonte A pouco espesso, com fraco grau de agregação e baixos teores de matéria orgânica, diretamente assente sobre a rocha (BRASIL, 1972).

Na microrregião do Cariri, $600.832,88$ ha encontra-se sob vegetação de caatinga, sendo $9.884,55$ ha de ocorrência em AFD (Figura 3). Essas áreas apresentam altitudes ligeiramente mais elevadas, com o relevo variando de suave ondulado a ondulado (Figura 3). Pastagens ocupam 225.963,60 ha no Cariri, onde 62.847,31 ha estão associados com AFD. Essas áreas são mais extensas em Gurjão, Juazeirinho, São João do Cariri, São José dos Cordeiros e Taperoá. Destacam-se ainda os 169.490,93 ha destinados à agropecuária, onde não é possível distinguir áreas agrícolas de pastagens, com 60.085,11 ha dessas atividades ocorrendo em AFD.

Áreas sem vegetação (15.781,54 ha) ocorrem notoriamente em topos de colinas arredondadas, vertentes longas com pequenas declividades e em sopés de encostas (BRASIL, 1972). AFD sem vegetação totalizam 8.677,03 ha, aos quais estão associados TCo típicos e vertissólicos juntamente com RLe e RRe lépticos. Ausência de cobertura vegetal aliada a pequena espessura do solum e a ocorrência de horizonte $A$ com baixos teores de matéria orgânica nesses solos aumentam sobremaneira a susceptibilidade dessas áreas à degradação.

\section{Propriedades e atributos dos solos}

\section{Seridó}

$\mathrm{Na}$ Tabela 1 são apresentadas propriedades morfológicas e atributos físicos e químicos de perfis representativos da microrregião do Seridó. No Seridó Oriental potiguar é expressiva a ocorrência de RLe em AFD (Figura 4). Esses solos possuem elevada susceptibilidade aos processos erosivos, pois 
Processos pedogenéticos e susceptibilidade dos solos à degradação no semiárido brasileiro
Rodrigo Santana Macedo

Raphael Moreira Beirigo

Beatriz Macêdo Medeiros

Victor Junior Lima Felix

Renato Francisco da Silva Souza Alexandre Pereira de Bakker

apresentam material de origem consolidado logo abaixo do horizonte $A$, o que impede a infiltração de água e aumenta o fluxo de água superficial. Tal fato justifica a ampla ocorrência de horizonte $A$ pouco espesso e com baixos teores de matéria orgânica (BRASIL, 1972). Os baixos teores de matéria orgânica também refletem o predomínio da fração areia, que apresentam baixa capacidade de estabilização dos constituintes orgânicos do solo. A erodibilidade desses horizontes é considerável devido aos seus elevados teores de argila dispersa em água e de silte, com ampla ocorrência de erosão do tipo laminar severa e em sulcos nessas áreas. Além da possibilidade de ablação (remoção) do horizonte superficial, também pode haver nessas áreas colmatação de vales e eutrofização de corpos hídricos, pois nesses solos são encontrados em superfície teores de $P$ entre $60-70 \mathrm{mg} \mathrm{kg}^{-1}$ (BRASIL, 1971).

Os RLe também ocorrem em associação com RRq. Esses últimos são mais espessos ( $\leq 90 \mathrm{~cm})$, não possuem contato lítico ou lítico fragmentário dentro de $50 \mathrm{~cm}$ e apresentam $\geq 25 \%$ de feldspatos potássicos oriundos do substrato granítico (BRASIL, 1971). Ocorrem em relevo plano que propicia maior percolação de água e, consequentemente maior alteração do material de origem por hidrólise, com maior espessura desses solos e com predomínio da textura arenosa dentro de $150 \mathrm{~cm}$ a partir da superfície do solo.

Tabela 1 - Propriedades morfológicas e atributos físicos e químicos de perfis de solos representativos da microrregião do Seridó do Rio Grande do Norte e Paraíba, região semiárida do Nordeste brasileiro.

\begin{tabular}{|c|c|c|c|c|c|c|c|c|c|c|c|}
\hline \multirow{2}{*}{$\mathrm{Hz}$} & \multirow{2}{*}{$\begin{array}{l}\text { Prof. } \\
\text { (cm) }\end{array}$} & \multirow{2}{*}{ Estrutura ${ }^{1}$} & \multicolumn{4}{|c|}{ Granulometria $(\%)^{2}$} & \multirow{2}{*}{$\begin{array}{c}\mathbf{V} \\
\%\end{array}$} & \multirow{2}{*}{$\frac{P}{\mathrm{mg} \mathrm{dm}^{-3}}$} & \multirow{2}{*}{$\frac{\text { COT }}{\mathrm{g} \mathrm{kg}^{-1}}$} & \multirow{2}{*}{$\begin{array}{c}\text { PST } \\
\%\end{array}$} & \multirow{2}{*}{$\mathrm{Ta} / \mathrm{Tb}$} \\
\hline & & & A & $\mathbf{S}$ & Ar & ADA & & & & & \\
\hline \multicolumn{12}{|c|}{ TCo - Luvissolo Crômico Órtico típico } \\
\hline $\mathrm{A} 1$ & $0-20$ & $\begin{array}{l}\text { fr,pm,gr; } \\
\text { fr,pm, bs }\end{array}$ & 53 & 36 & 11 & 11 & 71 & 14 & 14,4 & 0,9 & 90 \\
\hline $\mathrm{A} 2$ & $20-33$ & $\mathrm{fr}, \mathrm{pe}, \mathrm{bs}$ & 42 & 35 & 23 & 21 & 87 & 3 & 9,4 & 1,2 & 76 \\
\hline IIBt & $33-40$ & $\mathrm{fm}, \mathrm{pm}, \mathrm{bs}$ & 28 & 26 & 46 & 42 & 95 & 2 & 5,7 & 1,3 & 56 \\
\hline$\| \mathrm{IC}$ & $40-50+$ & fr,pe,bs & 30 & 24 & 36 & 32 & 100 & 1 & 3,7 & 1,6 & 71 \\
\hline \multicolumn{12}{|c|}{ TCo - Luvissolo Crômico Órtico vertissólico } \\
\hline A1 & $0-4$ & $\mathrm{fr}, \mathrm{pm}, \mathrm{bs}$ & 53 & 33 & 14 & 11 & 79 & 3 & 13,6 & 2 & 73 \\
\hline $\mathrm{A} 2$ & $4-18$ & ma & 53 & 26 & 21 & 15 & 87 & 1 & 6,3 & 1 & 45 \\
\hline $\mathrm{Bt}$ & $18-50$ & $\begin{array}{l}\text { mo,mg,pr; } \\
\text { mo,mg,ba }\end{array}$ & 37 & 23 & 40 & 37 & 95 & $<1$ & 2,5 & 3 & 59 \\
\hline C & $50-65$ & - & - & - & - & - & - & - & - & - & - \\
\hline \multicolumn{12}{|c|}{ SXe - Planossolo Háplico Eutrófico solódico } \\
\hline$A$ & $0-8$ & fr,pe,gr & 60 & 29 & 11 & 8 & 56 & 60 & 15,4 & 3,4 & 102 \\
\hline $\mathrm{Bt}$ & $8-22$ & $\begin{array}{c}\text { fo,gr,co; } \\
\text { mf,mg,ba/bs }\end{array}$ & 51 & 17 & 32 & 28 & 83 & 3 & 7,8 & 5,9 & 47 \\
\hline$C$ & $22-45$ & $\begin{array}{c}\text { fo,gr,co; } \\
\text { mf,mg,ba/bs }\end{array}$ & 62 & 15 & 23 & 23 & 100 & 12 & 4,3 & 19,1 & 50 \\
\hline \multicolumn{12}{|c|}{ RLe - Neossolo Litólico Eutrófico típico } \\
\hline A & $0-25$ & fr,pm,gr & 68 & 25 & 7 & 7 & 85 & 62 & 6,5 & 1,6 & 97 \\
\hline $\mathrm{R}$ & - & - & - & - & - & - & - & - & - & - & - \\
\hline \multicolumn{12}{|c|}{ RRq - Neossolo Regolítico Psamítico fragipânico } \\
\hline$A$ & $0-20$ & gs & 89 & 15 & 1 & 1 & 100 & 5 & 3,0 & 2,7 & 110 \\
\hline C1 & $20-50$ & gs & 85 & 13 & 2 & 2 & 100 & 2 & 1,0 & 3,3 & 30 \\
\hline $\mathrm{C} 2$ & $50-85$ & gs & 81 & 15 & 4 & 4 & 46 & 1 & 1,0 & 2,3 & 33 \\
\hline C3x & $85-100$ & $\mathrm{ma}$ & 79 & 13 & 8 & 6 & 42 & 2 & 1,0 & 2,6 & 24 \\
\hline
\end{tabular}

Fonte - Brasil (1971; 1972). Organizado pelos autores, 2020. 
Processos pedogenéticos e susceptibilidade dos solos à degradação no semiárido brasileiro
Rodrigo Santana Macedo

Raphael Moreira Beirigo

Beatriz Macêdo Medeiros

Victor Junior Lima Felix

Renato Francisco da Silva Souza Alexandre Pereira de Bakker

Hz: horizonte; Prof: profundidade; V\%: saturação por bases; P: fósforo disponível; COT: carbono orgânico total; PST: percentagem de saturação por sódio; Ta/Tb: atividade da fração argila (Ta: atividade alta; Tb: atividade baixa);

${ }^{1}$ grau de desenvolvimento: $\mathrm{fr}$ (fraco), fm (fraco a moderado); mo (moderado), moderado a forte (mf), fo (forte); tamanho: pe (pequeno), pequeno e médio $(\mathrm{pm})$, médio a grande $(\mathrm{mg})$, gr (grande); tipo: bs (blocos subangulares), ba (blocos angulares), pr (prismática), co (colunar), gr (granular), gs (grãos simples), ma (maciça);

${ }^{2}$ A: areia; S: silte; Ar: argila; ADA: argila dispersa em água

Os RRq também são susceptíveis aos processos erosivos, devido aos baixos teores de argila e de matéria orgânica dos horizontes superficiais, que Ihes conferem uma estrutura do tipo grãos simples (Tabela 1). Somado a isso, praticamente toda a argila presente é dispersa em água, e os teores de óxidos de ferro, que poderiam atuar como agentes cimentantes, são baixos, fato esse inferido pela coloração acinzentada dos horizontes e pelos valores de $\mathrm{Kr} \geq 0,75$ (BRASIL, 1971). Essas propriedades e atributos são comuns aos RR do semiárido brasileiro (SANTOS et al, 2012).

Algumas características dos $\mathrm{RRq}$ requerem atenção especial, a saber: a) incremento abrupto de argila entre os subhorizontes $C$, não associado com horizonte $B$ textural; b) aumento do grau de coesão e diminuição da friabilidade em profundidade (horizonte fragipânico), e; c) mosqueados em profundidade indicando restrição de drenagem. Dada a profundidade de ocorrência, essas camadas provavelmente não imprimem restrições físicas e de aeração ao desenvolvimento das culturas, haja vista a ampla utilização desses solos para fins agrícolas (BRASIL, 1971). Entretanto, o caráter fragipânico também pode ocorrer próximo a superfície, o que pode influenciar negativamente no crescimento de raízes e aumentar o escoamento superficial.

Figura 4 - Unidades de levantamento de solos sobrepostas às áreas fortemente degradadas na microrregião do Seridó (Rio Grande do Norte e Paraíba) e Cariri (Paraíba), região semiárida do Nordeste brasileiro.
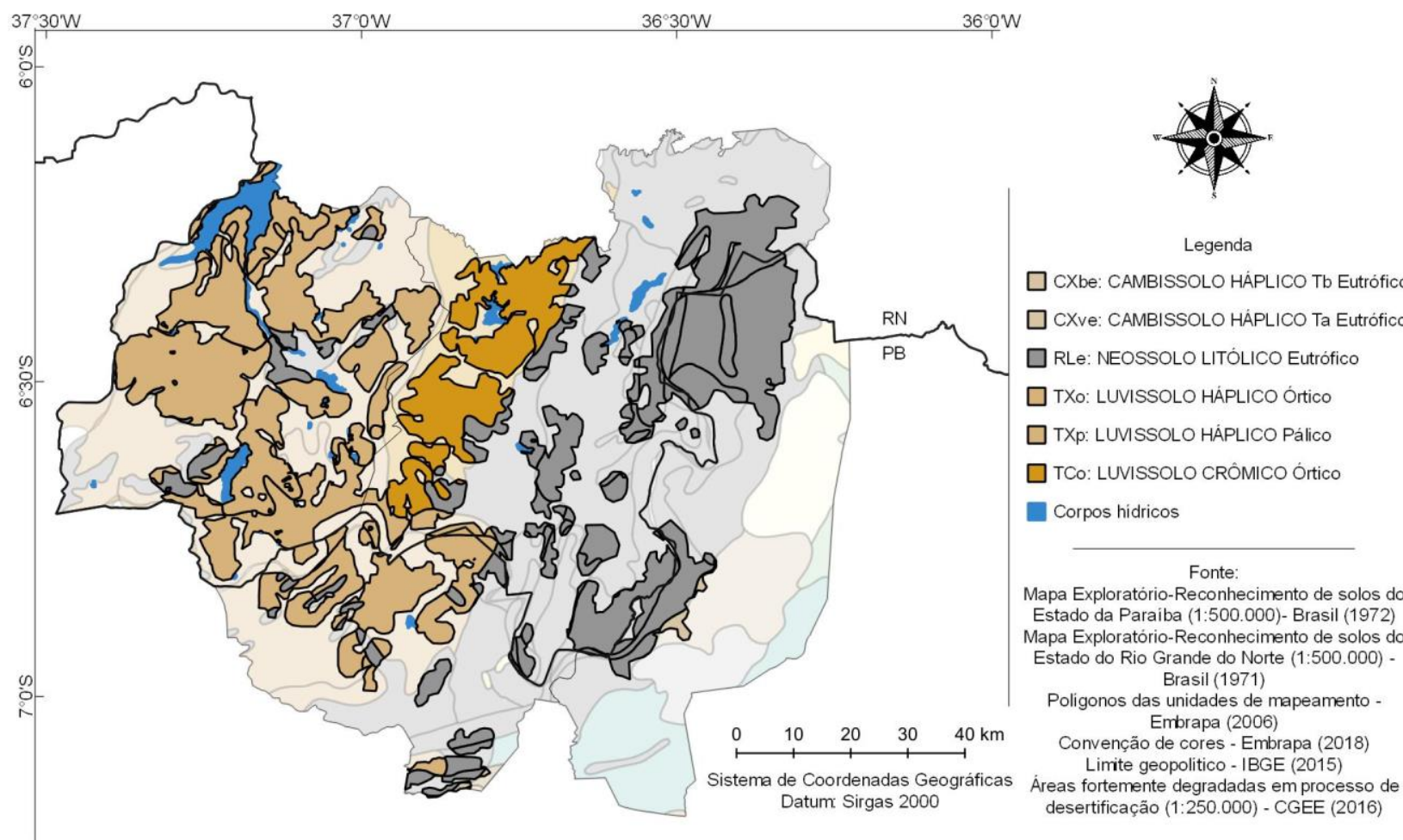

Org. - Autores, 2020. 
Os SXe ocorrem como segundo ou terceiro componente das associações com os $T X, R L$ e os RR (Tabela 1; Figura 2). Ocorrem em relevo plano com declividade de até $3 \%$ e são formados predominantemente a partir de gnaisse cataclástico com biotita e metassomatito de composição granítica. Essas rochas apresentam consideráveis teores de minerais facilmente intemperizáveis, como feldspatos potássicos, biotita e anfibólios com diferentes graus de intemperismo (BRASIL, 1971).

Os Planossolos com considerável dissolução de minerais primários apresentam maiores teores de argila, indicando que a formação de argila in situ (argilização) é um processo pedogenético importante nesses solos (SOUSA et al., 2020). Evidências desse processo são a menor quantidade de minerais facilmente intemperizáveis, incremento absoluto de argila e maiores teores de $\mathrm{Ca}^{2+}$ no horizonte $\mathrm{Bt}$ em relação ao Cr (BRASIL, 1971; SOUSA et al., 2020). Tal fato também contribui para a mudança textural abrupta, o que torna esses solos mais susceptíveis as perdas de horizonte superficial por erosão laminar severa e ravinamentos, pois a menor permeabilidade do horizonte Bt impede e/ou diminui a infiltração de água, favorecendo o arraste do material sobrejacente.

Nos SXe o horizonte A geralmente é pouco espesso $(<10 \mathrm{~cm})$, ocorrendo solos onde o horizonte $A$ pode alcançar $15 \mathrm{~cm}$, quando sob drenagem imperfeita, ou locais onde o horizonte $A$ foi totalmente removido (BRASIL, 1971). Os Planossolos de áreas mais úmidas da região nordeste apresentam horizonte $A$ e $E$ mais espesso, enquanto os que ocorrem em áreas de clima semiárido não desenvolvem horizonte eluvial e o A apresenta espessura média de $15 \mathrm{~cm}$ (FERREIRA et al., 2016). Nos Planossolos truncados (remoção do horizonte A), os processos erosivos podem expor em superfície horizontes com elevados teores de sódio e de sais, pouco permeáveis e com considerável teor de argila dispersa em água. Além da perda de matéria orgânica e de cátions básicos com a retirada do horizonte superficial, esse processo erosivo também pode promover a eutrofização de corpos hídricos, à semelhança das áreas com RLe nas quais ocorrem associados.

Os TCo são mais representativos em Caicó, Cruzeta, Ouro Branco e na porção ocidental de Acari no Rio Grande do Norte. Nessas áreas ocorre como componente principal, ocupando uma área de 55.834, 473 ha (Tabela 1; Figura 2). Em geral são pouco profundos $(50-100 \mathrm{~cm})$, com argila de atividade muito alta (50-60 $\left.\mathrm{cmol}_{\mathrm{c}} \mathrm{kg}^{-1}\right)$ e com elevada saturação por bases (BRASIL, 1971). Essas características são comumente encontradas em Luvissolos em toda a extensão do semiárido brasileiro (OLIVEIRA et al., 2008).

O horizonte A dos TCo possui fraco grau de desenvolvimento da estrutura, tem evidência de material pseudoalóctone em sua formação, é duro ou muito duro quando seco e apresenta elevados teores de argila dispersa em água (BRASIL, 1971). Tais características provavelmente acarretam em perda preferencial de argilas e silte fino (elutriação), processo esse favorecido pela ocorrência de chuvas com elevada intensidade e a baixa condutividade hidráulica dos horizontes subsuperficiais, que favorecem fluxo hídrico superficial (OLIVEIRA et al., 2008).

Semelhante aos Planossolos, a mudança textural abrupta dos Luvissolos também aumenta sua susceptibilidade aos processos erosivos, especialmente por estes ocorrerem predominantemente em terço médio e inferior de vertentes em relevos suavemente ondulados. Quando em relevo ondulado, a espessura máxima do horizonte $A$ é de $12 \mathrm{~cm}$, indicando consideráveis perdas de solo nessas posições. A elevada pedregosidade em superfície, constituída por quartzos rolados, desarestados ou semidesarestados (BRASIL, 1971), confirma a contribuição alóctone na gênese desses solos.

A gênese dos Luvissolos envolve a atuação da bissialitização coexistindo com monossiliatização (BARBOSA et al., 2014). Nesses processos perdas parciais de silício e bases trocáveis criam 
condições para a (neo)formação de argilas. Cloritas nas frações grossas também indicam argilas herdadas do material de origem (BRASIL, 1971). Durante a evolução desses solos também há considerável formação de óxidos de ferro secundários. A formação de hematita, responsável pelo avermelhamento dos solos (rubeificação), é favorecida pelo aporte de teores elevados de Fe, elevada temperatura ou baixa atividade de água, $\mathrm{pH}$ próximo da neutralidade e baixos teores ou rápida mineralização de matéria orgânica (TORRENT; GUZMAN; PARRA, 1982; JOHNSTON e LEWIS, 1983; SCHWERTMANN e MURAD, 1983). Essa rubeificação é apontada como um dos principais processos pedogenéticos dentre os Luvissolos Crômicos da região semiárida brasileira (OLIVEIRA et al., 2009; SILVA, 2018).

Em Caicó-RN ocorrem TCo fragmentários. Diferem dos TCo típicos por apresentarem contato lítico fragmentário (rocha semi intemperizada) dentro dos primeiros $50 \mathrm{~cm}$, o que também possibilita a penetração de raízes e a infiltração de água. Dado os teores de equivalente de umidade maiores (25$30 \%$ ) nos horizontes Bt e no saprolito (BRASIL, 1971), provavelmente nos períodos secos as raízes têm maior atividade nesses horizontes, contribuindo para o intemperismo da rocha e fragmentação do contato lítico.

A ocorrência de horizonte $\mathrm{C} / \mathrm{R}$ nesses solos indica que ocorrem fragmentos de rocha dentro dos primeiros $40 \mathrm{~cm}$, que por sua natureza impermeável podem contribuir para enxurradas em épocas de chuvas concentradas. Nessas áreas predomina caatinga hiperxerófila aberta e horizontes superficiais com baixos teores de matéria orgânica e argila e, portanto, baixa proteção ao potencial erosivo das chuvas e formação de estrutura com fraco grau de agregação, aumentando a susceptibilidade desses solos à erosão.

Nas AFD do Seridó Ocidental potiguar predominam TXp abrúpticos (Figura 4). São solos com profundidade do solum maior que $80 \mathrm{~cm}$, sem contato lítico ou lítico fragmentário e que possuem saprolito com $10 \mathrm{~cm}$ de espessura. Essas evidências apontam para maior efetividade da hidrólise no intemperismo do material de origem, mais susceptível às transformações devido a considerável participação de minerais facilmente intemperizáveis em sua composição, tais como hornblenda e outros anfibólios (BRASIL, 1971). Tal fato corrobora prévios estudos de que a gênese de Luvissolos mais profundos $(130-200 \mathrm{~cm})$ no semiárido está associada com o intemperismo de minerais facilmente intemperizáveis e posterior neoformação de argila (BÉTARD et al., 2009; BARBOSA et al., 2014).

Os TXp também apresentam mudança textural abrupta devido a descontinuidade litológica. São formados pelos processos pedogenéticos supracitados, mas adicionalmente tem maior participação da pedoturbação, melanização, inferida pelas cores mais enegrecidas no horizonte 2Bt 1 , solodização (caráter solódico), salinização (caráter salino no horizonte Bt) e vertização (caráter vértico) nos horizontes subsuperficiais $(10-80 \mathrm{~cm})$ (BRASIL, 1971).

Os sais em quase sua totalidade apresentam $\mathrm{Na}^{+}$em sua composição e, nos níveis encontrados nesses solos, podem interferir no crescimento da maioria das culturas, tendo em vista a ocorrência nos primeiros $12 \mathrm{~cm}$ do solo, zona de maior influência do sistema radicular. A principal fonte desses sais é o intemperismo de plagioclásios, presentes entre 30-40\% da composição mineralógica dos horizontes subsuperficiais e do saprolito (BRASIL, 1971), associado às elevadas taxas de evapotranspiração de até 2200 mm/ano (GIONGO et al., 2018). Os maiores teores de sais no Bt e semelhante quantidade de minerais fontes desses sais no Bt e saprolito, sugerem que parte desses sais ascendem por capilaridade em períodos com elevadas taxas de evapotranspiração (RIBEIRO; RIBEIRO FILHO; JACOMINE, 2016). Isso causa o aumento da pressão osmótica da solução dos solos, o que pode diminuir a disponibilidade de água para as plantas. 
As áreas com RLe no Seridó paraibano são geralmente extremamente erodidas, dado a quantidade expressiva de afloramentos rochosos, relevo variando de ondulado a montanhoso e vertentes amplas e convexas que atuam como dissipadoras dos fluxos de água (BRASIL, 1972). Essa forte declividade contribui para a ocorrência de horizonte $A$ pouco espesso, que aliado a vegetação de caatinga hiperxerófila arbustiva aberta explicam os extremamente baixos teores de $C$ orgânico em superfície ( $\leq$ 0,5\%) (HAZELTON e MURPHY, 2017). Essas características justificam a ampla ocorrência desses solos em AFD do Seridó Oriental paraibano (Figura 4).

TCo típicos e vertissólicos predominam nas AFD do Seridó Ocidental paraibano. Apesar de semelhantes aos encontrados nos Seridó potiguar, a elevada mudança textural abrupta, menor profundidade média $(60-70 \mathrm{~cm})$ e a ampla ocorrência em vertentes com dezenas de metros os tornam mais susceptíveis aos processos erosivos (Tabela 1). Nessas áreas é comum a ocorrência de erosão laminar com grau moderado a severo e horizonte A pouco espesso, mesmo quando sob vegetação arbustiva densa e em relevo suave ondulado, confirmando a relação direta entre a mudança textual abrupta e a elevada susceptibilidade desses solos a erosão (BRASIL, 1972).

Os CXbe latossólicos ocorrem em relevo ondulado e encontram-se severamente erodidos (BRASIL, 1972). Os CXve diferem dos CXbe pela presença de contato lítico dentro de $50 \mathrm{~cm}$ e pela maior restrição de drenagem, o que explica sua ocorrência em associação com SXo. Nas áreas onde ocorrem os CXve a erosão é laminar a severa, indicando a forte relação entre relevo, solos e degradação (Figura 2). Tais fatos justificam a ocorrência desses solos em pequenas AFD no Seridó Oriental paraibano.

\section{Cariri}

No Cariri não foram encontrados TXp abrúpticos e TCo fragmentários como no Seridó do Rio Grande do Norte. As evidências apontam que a ação do clima sob relevo predominantemente suave ondulado e substrato muscovita-biotita-xisto e bitotita-xisto no Seridó potiguar propicia maiores condições para atuação da hidrólise e, consequentemente, aprofundamento do solum. Sob essas condições, o contato lítico é fragmentário e há condições mais favoráveis para a formação de argila nos horizontes subsuperficiais, contribuindo para a instalação da mudança textural abrupta. O Cariri tem uma superfície com considerável grau de dissecamento, e sua leve inclinação em relação ao Sul do estado conduz seus cursos d'água intermitentes para o rio Paraíba, o que a torna fortemente trabalhada pela erosão e constituída por solos rasos a medianamente profundos (BRASIL, 1972).

Nas AFD no Cariri predominam TCo (Tabela 2; Figura 5). Esses Luvissolos apresentam mudança textural abrupta, argila de atividade alta e ocorrem predominantemente em relevo suave ondulado (Tabela 2). Muitos desses solos apresentam caráter vertissólico e encontram-se associados com VXo e RRe lépticos. Essa associação demonstra o desenvolvimento restrito desses solos, em que pese nos dois primeiros a drenagem restrita, dada a baixa permeabilidade dos horizontes diagnósticos e/ou localização em setores abaciados da paisagem, e nos $R R e$ o relevo ondulado.

Os Neossolos apresentam considerável representatividade territorial dentro do Cariri, em sua maioria representados pelos RRe, seguido dos RLe e Neossolos Quartzarênicos Órticos (RQo) (Tabela 2; Figura 2). Dentre esses, os RLe são os solos mais associados com as AFD (Figura 5). Esses solos apresentam menor expressão dos processos pedogenéticos em decorrência do relevo ondulado e montanhoso. Devido à elevada rochosidade, pedregosidade e ampla associação com afloramentos rochosos, essas áreas não são intensamente cultivadas e em quase sua totalidade são mantidas com vegetação natural (BRASIL, 1972). Os RRe apresentam em geral contato lítico fragmentário entre 50$60 \mathrm{~cm}$, em que o horizonte $\mathrm{C}$ com teores de sódio próximos aos requeridos para caráter solódico inicia a partir de $25 \mathrm{~cm}$ (Tabela 2). 
Processos pedogenéticos e susceptibilidade dos solos à degradação no semiárido brasileiro
Rodrigo Santana Macedo

Raphael Moreira Beirigo

Beatriz Macêdo Medeiros

Victor Junior Lima Felix

Renato Francisco da Silva Souza Alexandre Pereira de Bakker

Tabela 2 - Propriedades morfológicas e atributos físicos e químicos de perfis de solos representativos da microrregião do Cariri na Paraíba, região semiárida do Nordeste brasileiro.

\begin{tabular}{|c|c|c|c|c|c|c|c|c|c|c|c|}
\hline \multirow{2}{*}{$\mathrm{Hz}$} & \multirow{2}{*}{$\begin{array}{l}\text { Prof. } \\
\text { (cm) }\end{array}$} & \multirow{2}{*}{ Estrutura } & \multicolumn{4}{|c|}{ Granulometria (\%) } & \multirow{2}{*}{$\begin{array}{c}\text { CE } \\
d S ~ m^{-1}\end{array}$} & \multirow{2}{*}{$\begin{array}{l}\mathbf{V} \\
\%\end{array}$} & \multirow{2}{*}{$\begin{array}{c}\text { COT } \\
\mathrm{g} \mathrm{kg}^{-1}\end{array}$} & \multirow{2}{*}{$\begin{array}{c}\text { PST } \\
\%\end{array}$} & \multirow{2}{*}{$\mathrm{Ta} / \mathrm{Tb}$} \\
\hline & & & A & $\mathbf{S}$ & $\mathrm{Ar}$ & ADA & & & & & \\
\hline \multicolumn{12}{|c|}{ TCo - Luvissolo Crômico Órtico vertissólico } \\
\hline $\mathrm{A} 1$ & $0-4$ & fr,pm.bs & 53 & 33 & 14 & 11 & - & 79 & 13,6 & 2 & 73 \\
\hline $\mathrm{A} 2$ & 4-18 & $\mathrm{ma}$ & 53 & 26 & 21 & 15 & - & 87 & 6,3 & 1 & 45 \\
\hline $\mathrm{Bt}$ & $18-50$ & $\begin{array}{c}\text { mo,mg,pr; } \\
\text { mo, me/gr, } \\
\text { ba }\end{array}$ & 37 & 23 & 40 & 37 & - & 95 & 2,5 & 3 & 59 \\
\hline $\mathrm{C}$ & $50-65$ & - & - & - & - & - & - & - & - & - & - \\
\hline
\end{tabular}

\begin{tabular}{|c|c|c|c|c|c|c|c|c|c|c|c|}
\hline \multicolumn{12}{|c|}{ RRe - Neossolo Regolítico Eutrófico léptico } \\
\hline A & $0-25$ & $\begin{array}{l}\mathrm{fr}, \mathrm{pm}, \mathrm{bs} ; \\
\mathrm{fr}, \mathrm{pm}, \mathrm{gr}\end{array}$ & 70 & 25 & 5 & 4 & - & 44 & 3,3 & 2 & 54 \\
\hline IIC1 & $25-40$ & - & 64 & 24 & 12 & 11 & - & 57 & 2,0 & 4 & 25 \\
\hline IIC2 & $40-55$ & $\mathrm{fr}, \mathrm{pm}, \mathrm{bs}$ & 54 & 32 & 14 & 8 & - & 59 & 1,9 & 3 & 29 \\
\hline \multicolumn{12}{|c|}{ SNo - Planossolo Nátrico Órtico gleissólico } \\
\hline A & $0-17$ & fr,pe,bs & 78 & 13 & 9 & 5 & - & 71 & 7,2 & 1 & 88 \\
\hline IIBt & $17-50$ & fo,gr,co & 61 & 13 & 26 & 22 & 1,0 & 78 & 5,8 & 8 & 60 \\
\hline IIC & $50-70$ & ma & 64 & 14 & 22 & 20 & 3,1 & 100 & 2,3 & 20 & 99 \\
\hline IIR & $70-80$ & - & - & - & - & - & - & - & - & - & - \\
\hline
\end{tabular}

\begin{tabular}{ccccccccccccc}
\hline \multicolumn{10}{c}{ VEo - Vertissolo Ebânico Órtico típico } \\
\hline A & $0-10$ & fr,pm,bs & 48 & 22 & 30 & 23 & 0,9 & 91 & 12,4 & 3 & 80 \\
C1 & $10-60$ & $\begin{array}{c}\text { mo,gr,pr; } \\
\text { fo,mg,ba }\end{array}$ & 39 & 17 & 44 & 36 & 0,9 & 96 & 7,0 & 4 & 78 \\
C2 & $60-95$ & $\begin{array}{c}\text { mo,me/gr,b } \\
\text { a }\end{array}$ & 38 & 20 & 42 & 36 & 2,5 & 100 & 3,4 & 5 & 79 \\
R & - & - & - & - & - & - & - & - & - & - & -
\end{tabular}

Fonte - Brasil (1972). Organizado pelos autores, 2020.

Hz: horizonte; Prof: profundidade; V\%: saturação por bases; P: fósforo disponível; COT: carbono orgânico total; PST: percentagem de saturação por sódio; Ta/Tb: atividade da fração argila (Ta: atividade alta; Tb: atividade baixa);

${ }^{1}$ grau de desenvolvimento: fr (fraco), mo (moderado), fo (forte); tamanho: pe (pequeno), pequeno a médio (pm), médio a grande (mg), gr (grande); tipo: bs (blocos subangulares), ba (blocos angulares), pr (prismática), co (colunar), gr (granular), ma (maciça);

${ }^{2}$ A: areia; S: silte; Ar: argila; ADA: argila dispersa em água.

Os RRe também podem ocorrer em associação com SNo (Figura 2). Esses últimos apresentam caráter solódico iniciando dentro de $15 \mathrm{~cm}$, portanto na zona de influência das raízes da maioria das culturas (Tabela 2). Os níveis de sais estão próximos aos requeridos para solo salino, podendo ascender por capilaridade nas épocas de elevada evapotranspiração e alcançar a superfície. Nesses solos o forte processo de perda de argila em superfície seguido de argiluviação leva a formação de um horizonte B extremamente duro e extremamente firme, de baixa permeabilidade, o que acarreta em diminuição da condutividade hidráulica e, por conseguinte, maior susceptibilidade aos processos erosivos. 
AFD com predomínio de SNo e VEo também ocorrem no Cariri (Figura 5). A ocorrência desses solos remete a condições de drenagem restrita, sendo que o relevo suave ondulado favorece a formação de solos mais rasos. Nessa associação os SNo são muito vulneráveis aos processos erosivos devido à baixa permeabilidade do horizonte plânico.

Figura 5 - Unidades de levantamento de solos sobrepostos às áreas fortemente degradadas na microrregião do Cariri (Paraíba). Semiárido brasileiro, região Nordeste, Brasil.
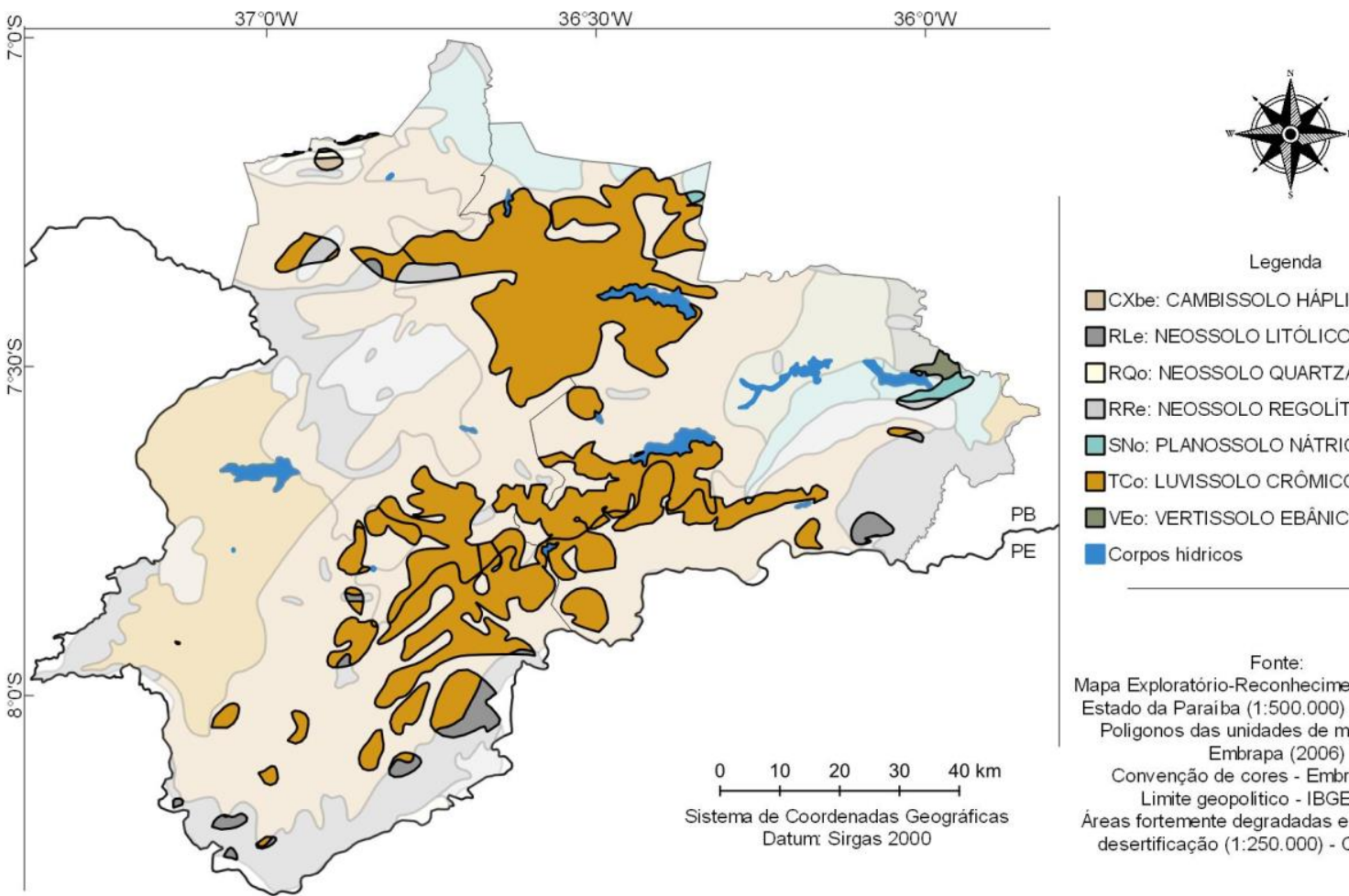

Org. - Autores, 2020.

A má drenagem também favorece a formação de VEo, componente principal na associação com TCo vertissólicos. Esses solos apresentam teores de carbono em superfície (Tabela 2), em partes creditado a caatinga arbustiva densa e à hidromorfia temporária. A pedoturbação e a vertização, que resulta em grande movimentação da massa do solo e fendilhamento expressivo, permite que partes do horizonte superficial sejam incorporadas aos horizontes $\mathrm{C}$, culminando com o escurecimento desses solos até maiores profundidades. Os baixos teores de carbono nos horizontes subsuperficiais confirmam que a melanização resulta da homogeneização de material nesses solos, e que sua estabilidade em maiores profundidades deve envolver associações estáveis com argilas expansivas (WATTEL-KOEKKOEK et al., 2001). A melanização de Vertissolos Ebânicos em região semiárida também tem sido creditada a paleoclima úmido, que favoreceu o desenvolvimento de vegetação densa e aporte de carbono nesses solos (LIMA, 2018).

\section{Relação morfogênese $x$ pedogênese $x$ desertificação}

Apesar da forte contribuição de material pseudoautóctone na gênese dos solos, notadamente dos horizontes superficiais, os solos encontrados no Seridó e Cariri Ocidental apresentam forte filiação genética com a geologia local. Os Luvissolos Crômicos/Háplicos, Neossolos Litólicos/Regolíticos e Planossolos Háplicos estão associados ao intemperismo de rochas que apresentam minerais máficos e plagioclásios, que ao sofrerem hidrólise liberam elementos em solução que recombinam-se e originam argilas (SOUSA et al., 2020), bem como, há liberação de argilas (cloritas e micas) dessas 
rochas para os solos. Tal fato é crucial para o aumento do teor de argila nos Planossolos e Luvissolos, nesses últimos ainda contribuindo para a formação de óxidos e, como consequência, a coloração avermelhada em subsuperfície.

Nas áreas onde os Neossolos Litólicos são os primeiros componentes das unidades de mapeamento destaca-se o micaxisto Seridó e os quartzitos da Formação Equador. Nesse caso, o relevo ondulado, forte ondulado ou montanhoso é um fator condicionante para a reduzida ação dos processos pedogenéticos, bem como, favorece o fluxo superficial em detrimento da infiltração de água e aprofundamento do solum, o que explica a ocorrência de solos rasos nesses locais. Em áreas com maior expressão do intemperismo químico, ocorrem Cambissolos Háplicos, e assim como os Neossolos Litólicos, são bastante vulneráveis aos processos erosivos devido o relevo movimentado.

No Seridó os Luvissolos, Planossolos e os Neossolos formados de micaxistos/quartzitos estão inseridos geomorfologicamente nas Superficies do Cristalino em áreas de pediplanação. Essas resultam de flutuações climáticas pretéritas, que perpassaram momentos mais úmidos, evidenciados pela ocorrência de inselbergs, e épocas de climas mais secos, em que os processos erosivos intensificados destruíram a continuidade da superfície dos grandes terrenos e desnudaram os menores, criando uma paisagem com relevo plano a suave ondulado com elevações residuais. Esse processo morfogenético ocasionou a deposição de materiais das partes mais elevadas na superfície dos solos das partes mais rebaixadas. Como resultado, tem-se a mudança textural abrupta, que aumenta a susceptibilidade desses solos aos processos erosivos.

Concomitantemente à morfogênese ocorreu a atuação dos processos pedogenéticos, que por sua vez, têm origem creditada a causas naturais e/ou antrópicas (Figura 6). Formação de argila in situ e neoformação mineral (Luvissolos e Planossolos), ferralitização (Latossolos), vertização (Planossolos e Luvissolos), rubeificação (Luvissolos) e silicificação (Neossolos) são de ocorrência exclusivamente natural. Comum aos solos tem-se o escurecimento dos constituintes inorgânicos por matéria orgânica (melanização), formação de agregados estruturais (pedalização) e a homogeneização e espessamento de horizontes por ação biológica (bioturbação).

A antrossolização no Seridó e Cariri é um importante processo pedogenético quando se avalia os mecanismos que culminam com a degradação das terras (Figura 6). Isso se dá pela sua capacidade de acelerar outros processos de ocorrência natural e, pelo fato de envolver processos pedogenéticos múltiplos (adição, perda, transformação e translocação), aos quais são desencadeados em resposta as variadas formas de exploração dos recursos do ambiente. Dentre outros fatores, cita-se o efeito direto da ação humana por meio de desmatamento, extração de produtos florestais, queimadas, sobrecarga animal e uso intensivo do solo e seu manejo inadequado (SÁ et al., 2010). De fato, estudo recente mostrou que a degradação das terras no semiárido brasileiro está relacionada com o inadequado e intenso manejo que explora os recursos naturais além da capacidade de suporte dos ecossistemas (TOMASELLA et al., 2018). Segundo esses autores a degradação aumentou devido as severas secas que afetaram a região desde 2011 e pelo aumento do desmatamento para produção de lenha e carvão vegetal.

As formas de utilização dos recursos de forma isolada ou em conjunto pode acelerar e/ou desencadear processos pedogenéticos específicos de ocorrência natural (p. ex., salinização, sodificação, solodização, entre outros). A título de demonstração, processos erosivos podem levar a ocorrência de sulcos de grau moderado a severo e ravinamentos, o que pode ocasionar tanto a ablação de horizontes superficiais, com perdas de matéria orgânica, como o empaledecimento do horizonte A. A ocorrência de horizontes superficiais pouco espessos com cores bruno-claraacinzentada (10YR 6/3), sob intensa utilização agrícola nos Cariri e no Seridó (BRASIL 1971; 1972), apontam para a ocorrência desses processos. Quando da ocorrência de erosão laminar ligeira, os processos erosivos podem também acelerar as perdas preferenciais de finos em superfície (elutriação), contribuindo para um aumento do gradiente textural. Em última análise, essas perdas de

Caminhos de Geografia Uberlândia-MG $\quad$ v. 22, n. 81 jun./2021 $\quad$ p. 176-195 Página 190


Processos pedogenéticos e susceptibilidade dos solos à degradação no semiárido brasileiro
Rodrigo Santana Macedo

Raphael Moreira Beirigo

Beatriz Macêdo Medeiros

Victor Junior Lima Felix

Renato Francisco da Silva Souza Alexandre Pereira de Bakker

solo, matéria orgânica e de argila por esses processos podem causar eutrofização e assoreamento de corpos hídricos e acarretar em redução da fertilidade dos solos, com impactos diretos na sua capacidade produtiva.

Notadamente nos solos que apresentam acúmulo de argila em subsuperfície (Luvissolos e Planossolos) e que são muito utilizados para fins agrícolas e pastagem, a antrossolização pode acelerar alguns processos pedogenéticos específicos (Figura 6). Nesse contexto, cita-se os TXp abrúpticos no Seridó Potiguar e os RLe no Seridó paraibano e Cariri, que apresentam solodização e salinização iniciando dentro dos primeiros $15 \mathrm{~cm}$ do solo. A princípio, a simples ocorrência de erosão por ações antrópicas nessas áreas pode exumar essas camadas subsuperficiais salinizadas e/ou solodizadas, com impactos diretos no desenvolvimento das plantas e no crescimento dos animais. Em outro cenário, a utilização de água salina ou irrigação sem sistema de drenagem ou a aplicação de fertilizantes com elevada concentração de sais nessas áreas pode levar o processo de salinização à condições que interferem no crescimento da maioria das culturas, p. ex., redução da absorção de água pelo aumento do potencial osmótico e toxidez por determinados elementos (PEDROTTI et al., 2015).

Figura 6 - Processos pedogenéticos específicos de ocorrência nos solos da microrregião do Seridó (Rio Grande do Norte e Paraíba) e Cariri (Paraíba), região semiárida do Nordeste, Brasil.

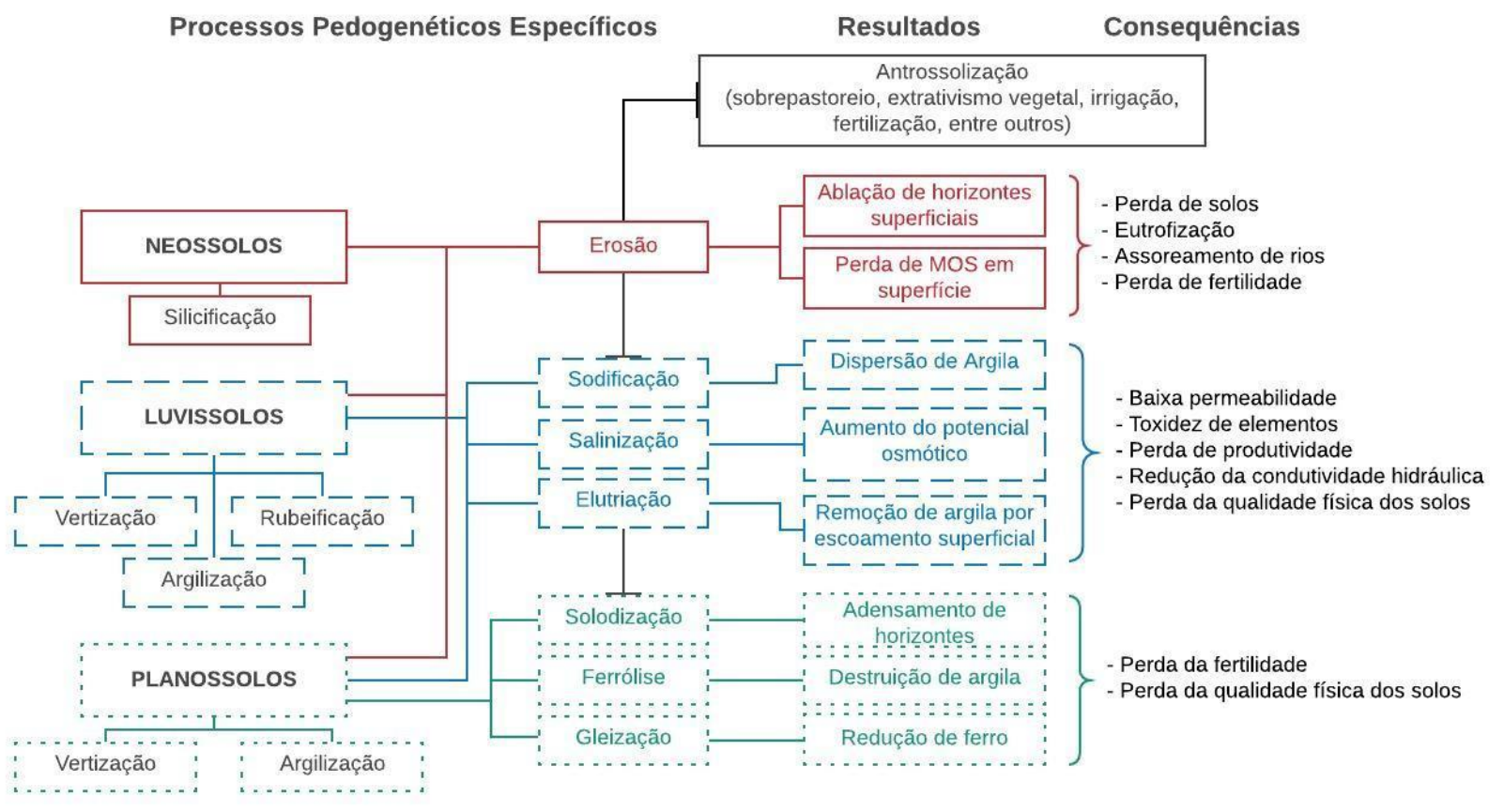

Org. - Autores, 2020.

A aplicação de sais por irrigação, em específico de $\mathrm{Na}^{+}$, pode culminar na iluviação de argila, com efeitos adversos na agregação dos solos. Esse processo resulta na formação de horizonte $\mathrm{A}$ ácido ( $\mathrm{pH} 5,8)$ e textura arenosa (9\% de argila) e um horizonte subsuperficial mais argiloso e com caráter sódico (Planossolo Nátrico). A argiluviação, acelerada indiretamente pelas ações antrópicas, pode aumentar o gradiente textural e propiciar a redução da condutividade hidráulica e da permeabilidade do horizonte Bt. Em períodos com precipitações torrenciais, típicas de regiões semiáridas, pode haver perdas consideráveis de solo por erosão hídrica. Outra implicação do adensamento dos horizontes subsuperficiais é a ocorrência de um ambiente redoximórfico no topo desses horizontes devido a 
presença de lençol suspenso (episaturação) (SOUSA et al., 2020). Sob tais condições, a ação sequencial da hidrólise e dessilicação culmina na destruição de argila dos horizontes superficiais (ferrólise), tornando-os mais ácidos e com menor capacidade de troca de cátions. Por envolver redução e oxidação de ferro, constatado pela ocorrência de mosqueados, esse processo coexiste com a gleização, em que pese a ambos às perdas na agregação dos solos, resultando em camadas maciças de baixa permeabilidade.

\section{CONSIDERAÇÕES FINAIS}

O material de origem e o relevo são fortes controladores da distribuição dos solos no Seridó (RN e $\mathrm{PB}$ ) e no Cariri (PB). Os Luvissolos, que apresentam maior evolução pedogenética, ocorrem predominantemente sob relevo suave ondulado e rochas com minerais máficos, enquanto a ocorrência em relevo ondulado, forte ondulado ou montanhoso é crucial para a reduzida ação dos processos pedogenéticos nos Neossolos e Cambissolos.

Mudança textural abrupta aliada às condições restritas de drenagem favorecem a formação de Planossolos, ao passo que expansão e contração da massa do solo devido a elevada atividade das argilas, podem originar Vertissolos ou solos com características vérticas como os Luvissolos e Planossolos.

Vertização (Luvissolos e Planossolos), silicificação (Neossolos Regolíticos) e rubeificação (Luvissolos) são processos de ocorrência exclusivamente natural. Soma-se a esses a formação de argila in situ, argiluviação e elutriação, responsáveis pela formação de horizonte B textural e mudança textural abrupta.

A ampla ocorrência de Luvissolos e Neossolos tanto em AFD sem cobertura vegetal ou com agropecuária quanto em locais com vegetação natural de caatinga densa, confirma que as atividades antrópicas exercem forte pressão sobre o ambiente.

Sob seus diversos aspectos, a ação humana (antrossolização) pode diretamente acelerar e/ou desencadear alguns processos pedogenéticos específicos, tais como erosão, elutriação, salinização e sodificação, cuja atuação em conjunto ou separado pode levar a perdas de matéria orgânica, ablação dos horizontes superficiais, assoreamento e eutrofização de corpos hídricos. A antrossolização também pode acelerar a dispersão de argilas, causando a redução da condutividade hidráulica dos horizontes subsuperficiais, aumentando a erosão dos solos e tornando as áreas mais susceptíveis a desertificação.

Os Neossolos Litólicos predominam nas AFD do Seridó Oriental (39\%), enquanto os Luvissolos Crômicos/Háplicos predominam nas AFD do Seridó Ocidental (57\%) e nos Cariris (89\%). Esses Luvissolos apresentam elevada susceptibilidade aos processos erosivos devido apresentarem mudança textural abrupta.

A remoção da vegetação natural acelera a erosão, que pode acarretar na perda do horizonte superficial e expor em superfície horizontes Bt extremamente duros e de baixa permeabilidade, com implicações diretas a infiltração de água e ao desenvolvimento da maioria das atividades agropecuárias locais e serviços ecossistêmicos associados. Com a erosão dos solos, pode haver deposição do material erodido nos corpos hídricos causando assoreamento e eutrofização, aumentando a susceptibilidade a desertificação.

\section{REFERÊNCIAS}

ALVARES, C. A.; STAPE, J. L.; SENTELHAS, P. C.; GONÇALVES, J. L. M.; SPAROVEK, G. Köppen's climate classification map for Brazil. Meteorologische Zeitschrift, v. 22, p. 711-728, 2013. http://doi: 10.1127/0941-2948/2013/0507. https://doi.org/10.1127/0941-2948/2013/0507

BARBOSA, W. R.; ROMERO, R. E.; SOUZA JÚNIOR, V. S. de; COOPER, M.; SARTOR, L. R.; PARTITI, C. S. de M.; JORGE, F. de O.; COHEN, R.; JESUS, S. L. de; FERREIRA, T. O. Effects of slope orientation on pedogenesis of altimontane soils from the Brazilian semi-arid region (Baturité

$\begin{array}{lllll}\text { Caminhos de Geografia } \quad \text { Uberlândia-MG } & \text { v. 22, n. } 81 & \text { jun./2021 } & \text { p. 176-195 Página } 192\end{array}$


massif, Ceará). Environmental Earth Science, v. 73, p. 3731-37432014. http://doi: 10.1007/s12665014-3660-4. https://doi.org/10.1007/s12665-014-3660-4

BÉTARD, F.; CANER, L.; GUNNELL, Y.; BOURGEON, G. Illite neoformation in plagioclase during weathering: evidence from semi-arid Northeast Brazil. Geoderma, v. 153, p. 53-62, 2009.

http://doi:10.1016/j.geoderma.2009.05.016. https://doi.org/10.1016/j.geoderma.2009.05.016

BRASIL - Ministério da Agricultura e do Interior. Levantamento exploratório-reconhecimento de solos do estado do Rio Grande do Norte. Recife, 1971.

BRASIL - Ministério da Agricultura e do Interior. Levantamento exploratório-reconhecimento de solos do estado da Paraíba. Rio de Janeiro, 1972.

CGEE - Centro de Gestão e Estudos Estratégicos. Desertificação, degradação da terra e secas no Brasil. Brasília, 2016.

EMBRAPA - Empresa Brasileira de Pesquisa Agropecuária. Solos do Nordeste. 2006. Disponível em: http://solos.uep.cnps.embrapa.br/. Acesso em: 19 de março de 2020.

EMBRAPA - Empresa Brasileira de Pesquisa Agropecuária. Sistema brasileiro de classificação de solos. 5 ed. Rio de Janeiro, 2018.

FERREIRA, J. T. P.; RIBEIRO FILHO, M. R.; RIBEIRO, M. R.; SOUZA JÚNIOR, W. S. de; BITTAR, S. M. B.; SANTOS, R. G. dos. Planosols developed in different geoenvironmental conditions in Northeastern Brazil. Revista Brasileira de Ciência do Solo, v. 40, p. e0150131, 2016. http://doi: 10.1590/18069657rbcs20150131. https://doi.org/10.1590/18069657rbcs20150131

GIONGO, V; MENDES, A. M. S.; ANGELOTTI, F.; TAURA, T. A.; LEITE, L. F. C.; CUNHA, T. J. F. Low carbon technologies for agriculture in dryland: Brazilian experience. In: RAO, C. S.; SHANKER, A. K.; SHANKER, C. (Coord.). Climate resilient agriculture - strategies and perspectives. Delhi: Indian Agricultural Research Institute, 2018. p. 105-127. https://doi.org/10.5772/intechopen.72363

HAZELTON, P.; MURPHY, B. Interpreting soil test results: What do all the numbers mean? Clayton: CSIRO Publishing, 2017. https://doi.org/10.1071/9781486303977

IBGE - Instituto Brasileiro de Geografia e Estatística. Manual técnico da vegetação brasileira: sistema fitogeográfico, inventário das formações florestais e campestres, técnicas e manejo de coleções botânicas, procedimentos para mapeamentos. Rio de janeiro, 2012.

IBGE - Instituto Brasileiro de Geografia e Estatística. Mapas: bases e referenciais. 2015. Disponível em: https://mapas.ibge.gov.br/bases-e-referenciais/bases-cartograficas.html. Acesso em: 23 de março de 2020.

JOHNSTON, J. H.; LEWIS, D. G. A detailed study of the transformation of ferrihydrite to hematite in an aqueous medium at $92^{\circ} \mathrm{C}$. Geochimical and Cosmochimical Acta, v. 47, p. 1823-1831, 1983. http://doi: 10.1016/0016-7037(83)90200-4. https://doi.org/10.1016/0016-7037(83)90200-4

LIMA, G. K. Pedogênese de Vertissolos em ambientes de formação contrastantes. Tese (Doutorado em Solos e Nutrição de Plantas) - Piracicaba: ESALQ/USP. 2018.

MAPBIOMAS - Mapeamento Anual da Cobertura e Uso do Solo no Brasil. 2019.. Disponível em: https://plataforma.mapbiomas.org/. Acesso em: 18 de setembro de 2020

MATALLO JUNIOR, H. Indicadores de desertificação: histórico e perspectivas. Brasília, 2001. Disponível em: https://unesdoc.unesco.org/ark:/48223/pf0000129871. Acesso em: 13 de março de 2020.

MEDEIROS, V. C de; NESI, J. de R.; NASCIMENTO, M. A. L do. Recursos Minerais. In: PFALTZGRAFF, P. A. dos S.; TORRES, F. S. de M. (Coord.). Geodiversidade do estado do Rio Grande do Norte. Rio de Janeiro: CPRM, 2010. p. 47-67.

MMA - Ministério do Meio Ambiente. Programa de Ação Nacional de Combate à Desertificação e Mitigação dos Efeitos da Seca PAN-Brasil. 2005. Disponível em:

https://www.mma.gov.br/estruturas/sedr_desertif/_arquivos/pan_brasil_portugues.pdf. Acesso em: 18 de abril de 2020 . 
OLIVEIRA, L. B de; FONTES, M. P. F.; RIBEIRO, M. R.; KER, J. C. Micromorfologia e gênese de Luvissolos e Planossolos desenvolvidos de rochas metamórficas no semiárido Brasileiro. Revista Brasileira de Ciência do Solo, v. 32, p. 2407-2423, 2008. http://doi: 10.1590/S010006832008000600019. https://doi.org/10.1590/S0100-06832008000600019

OLIVEIRA, L. B.; FONTES, M. P. F.; RIBEIRO, M. R.; KER, J. C. Morfologia e classificação de Luvissolos e Planossolos desenvolvidos de rochas metamórficas no semiárido do nordeste brasileiro. Revista Brasileira de Ciência do Solo, v. 33, p. 1333-1345, 2009. http://doi: 10.1590/S010006832009000500026. https://doi.org/10.1590/S0100-06832009000500026

PEDROTTI, A.; CHAGAS, R. M.; RAMOS, V. C.; PRATA, A. P. do N.; ARIOVALDO, A. T. L.; SANTOS, P. B. Causas e consequências do processo de salinização dos solos. Revista Eletrônica em Gestão, Educação e Tecnologia Ambiental, v. 19, p. 1308-1324, 2015. http://doi: 105902/2236117016544.

PEREZ-MARIN, A. M.; CAVALCANTE, A. M. B.; MEDEIROS, S. S. de; TINÔCO, L. B. M.; SALCEDO, I. H. Núcleos de desertificação no semiárido brasileiro: ocorrência natural ou antrópica? Parcerias Estratégicas, v. 17, p. 87-106, 2012.

QGIS DEVELOPMENT TEAM. QGIS geographic information system. 2020. Disponível em: http://qgis.osgeo.org. Acesso em: 19 de maio de 2020.

RIBEIRO, M. R.; RIBEIRO FILHO, M. R.; JACOMINE, P. K. T. Origem e classificação dos solos afetados por sais. In: GHEYI, H. R.; DIAS, N. da S.; LACERDA, C. F. de; GOMES FILHO, E. (Coord.). Manejo da salinidade na agricultura: Estudos básicos e aplicados. Fortaleza: INCTSal, 2016. p. 916.

SÁ, I. B.; CUNHA, T. J. F.; ANGELOTTI, F.; DRUMOND, M. A. Processos de desertificação no semiárido brasileiro. In: SÁ, I. B.; SILVA, P. C. G. da. (Coord.). Semiárido brasileiro: pesquisa, desenvolvimento e inovação. Petrolina: Embrapa Semiárido, 2010. p. 126-158.

SANTOS, E. J.; FERREIRA, C. A.; da SILVA JUNIOR., J. M. F. da (Org.). Geologia e recursos minerais do Estado da Paraíba. Recife: CPRM, 2002. https://doi.org/10.1590/S0103$\underline{40142002000200009}$

SANTOS, J. C. B. dos; SOUZA JUNIOR, V. S.; CORREAA, M. M.; RIBEIRO, M. R.; ALMEIDA, M. da. C.; BORGES, L. E. P. Caracterização de Neossolos Regolíticos da região semiárida do estado de Pernambuco. Revista Brasileira de Ciência do Solo, v. 36, p. 683-695, 2012.

https://doi.org/10.1590/S0100-06832012000300001. https://doi.org/10.1590/S0100$\underline{06832012000300001}$

SCHWERTMANN, U.; MURAD, E. Effect of $\mathrm{pH}$ on the formation of goethite and hematite from ferrihydrite. Clay Clay Minerals, v. 31, p. 277-284, 1983. http://doi.org/10.1346/CCMN.1983.0310405. https://doi.org/10.1346/CCMN.1983.0310405

SILVA, F. H. B. B.; BURGOS, N.; ACCIOLY, L. J. de O.; COSTA, T. C. C.; OLIVEIRA, M. A. J. Caracterização dos recursos naturais de uma área piloto do Núcleo de Desertificação do Seridó, Estados do Rio Grande do Norte e da Paraíba. 2002. Disponível em:

https://www.embrapa.br/busca-de-publicacoes/-/publicacao/338376/. Acesso em: 12 de abril de 2020.

SILVA, V. R. F. Gênese de Luvissolos ao longo de uma climossequência sobre anfibolito no semiárido de Pernambuco. Dissertação (Mestrado em Ciência do Solo) - Recife: UFRPE, 2018.

SOUSA, F. P.; FERREIRA, T. O.; MENDONÇA, E. S.; ROMERO, R. E.; OLIVEIRA, J. G. B. Carbon and nitrogen in degraded Brazilian semi-arid soils undergoing desertification. Agriculture, Ecosystems \& Environment, v. 148, p. 11-21, 2012. http://doi.org/10.1016/j.agee.2011.11.009. https://doi.org/10.1016/j.agee.2011.11.009

SOUSA, J. E. S., SANTOS, J. C. B. dos; CORREA, M. M.; NASCIMENTO, A. F. do; SCHULZE, S. M. B. B.; FERREIRA, T. O.; ARAUJO FILHO, J. C. de; SOUZA JUNIOR; V. S. de. Mineralogy and genesis of Planosols under a semi-arid climate, Borborema Plateau, NE Brazil. Catena, v. 184, p. 104260, 2020. http://doi: 10.1016/j.catena.2019.104260. https://doi.org/10.1016/j.catena.2019.104260 
SOUZA, D. C. de; OYAMA, M. D. Climatic consequences of gradual desertification in the semi-arid area of Northeast Brazil. Theoretical and Applied Climatology, v. 103, p. 345-357, 2011. https://doi.org/10.1007/s00704-010-0302-y

SOUZA JUNIOR, C. M. et al. Reconstructing three decades of land use and land cover changes in brazilian biomes with Landsat archive and earth engine. Remote Sensing, v. 12, 2735, 2020. https://doi.org/10.3390/rs12172735. https://doi.org/10.3390/rs12172735

SUDENE - Superintendência do Desenvolvimento do Nordeste. Delimitação do Semiárido. 2017. Disponível em: http://www.sudene.gov.br/delimitacao-do-semiárido. Acesso em: 13 de maio de 2020.

TOMASELLA, J.; VIEIRA, R. M. S. P.; BARBOSA, A. A.; RODRIGUEZ, D. A.; SANTANA, M. de O.; SESTINI, M. F. Desertification trends in the Northeast of Brazil over the period 2000-2016.

International Journal of Applied Earth Observation and Geoinformation, v. 73, p. 97-206, 2018. http://doi.org/10.1016/j.jag.2018.06.012. https://doi.org/10.1016/j.jag.2018.06.012

TORRENT, J.; GUZMAN, R.; PARRA, M. A. Influence of relative humidity on the crystallization of Fe (III) oxides from ferrihydrite. Clay Clay Minerals, v. 90, p. 337-340, 1982. http://doi: 10.1346/CCMN.1982.0300503. https://doi.org/10.1346/CCMN.1982.0300503

UNCCD - United Nations Convention to Combat Desertification. Regions: Africa. 2017. Disponível em: https://www.unccd.int/sites/default/files/relevant-links/2017-01/UNCCD_Convention_ENG_0.pdf.

VASCONCELOS SOBRINHO, J. Identificação de processos de desertificação no Polígono das Secas do Nordeste Brasileiro. Recife. SUDENE. 1978.

VENDRUSCOLO, J.; PEREZ MARIN, A. M.; FELIX, E. dos S.; FERREIRA, K. R.; CAVALHEIRO, W. C. S.; FERNANDES, I. M. Monitoring desertification in semi-arid Brazil: using the Desertification Degree Index (DDI). Land Degradation \& Development, 2020. No prelo. http://doi: 10.1002/ldr.3740. https://doi.org/10.1002/ldr.3740

VIEIRA, R. M. S. P.; TOMASELLA, J.; ALVALÁ, R. C. S.; SESTINI, M. F.; AFFONSO, A. G.; RODRIGUEZ, D. A.; BARBOSA, A. A.; CUNHA, A. P. M. A.; VALLES, G. F.; CREPANI, E.; de OLIVEIRA, S. B. P.; de SOUZA, M. S. B.; CALIL, P. M.; de CARVALHO, M. A.; VALERIANO, D. M.; CAMPELLO, F. C. B.; SANTANA, M. O. Identifying areas susceptible to desertification in the Brazilian northeast. Solid Earth, v. 6, p. 347-360, 2015. htpp://doi.org/10.5194/se-6-347-2015, 2015. https://doi.org/10.5194/se-6-347-2015

WATTEL-KOEKKOEK, E. J. W.; VAN GENUCHTEN, P. P. L.; BUURMAN, P.; VAN LAGEN, B. Amount and composition of clay-associated soil organic matter in a range of kaolinitic and smectitic soils. Geoderma, v. 99, p. 27-49, 2001. htpp://doi: 10.1016/S0016-7061(00)00062-8. https://doi.org/10.1016/S0016-7061(00)00062-8

WILDING, L. P.; SMECK, N. E.; HALL, G. F. (Org.) Pedogenesis and Soil Taxonomy. I. Concepts and interactions. Amsterdam: Elsevier, 1983a.

WILDING, L. P.; SMECK, N. E.; HALL, G. F. (Org.). Pedogenesis and Soil Taxonomy. II. The soil orders. Amsterdam: Elsevier, 1983b.

YOUNG, A. Tropical soils and soil survey. Cambridge: Cambridge University Press, 1976.

Recebido em: 11/06/2020

Aceito para publicação em: 10/11/2020 